\title{
Análise semiótica do vídeo "assim é ser criança": o papel do jogo de faz-de-conta no protagonismo e autoria das crianças
}

\author{
Victor Reis Mazzei \\ Rodrigo Lema del Rio Martins? \\ Roquel Firmino Magalhães Barbosa 3 \\ André da Silva Mello 4
}

\section{RESUMO}

O artigo focaliza o vídeo de animação "Assim é ser criança", do Mundo Bita, cujas exibições acontecem na rede social Youtube. O objetivo do estudo é analisar, a partir dessa animação, o papel do jogo de faz-de-conta nas criações infantis. Criatividade, ludicidade e produção cultural são alguns traços exibidos pelos personagens infantis no vídeo em questão nesse artigo e servem como reflexão para que professores repensem suas práticas pedagógicas no intuito de valorizar o protagonismo das crianças em suas aulas. No processo de análise, utiliza-se o método semiótico proposto por Charles Sanders Peirce, em diálogo com a Sociologia da Infância e com os Estudos do Cotidiano, para interpretação dos signos e na desocultação dos sentidos propostos pelos criadores desse material audiovisual.

Palavras-chave: Semiótica. Faz-de-conta. Sociologia da infância. Estudos com o cotidiano

1 Doutorando em Educação Física pela Universidade Federal do Espírito Santo (UFES). Professor do curso de Publicidade e Propaganda da Faculdade Integrada Espírito Santense (FAESA). Vitória/Espírito Santo, Brasil. E-mail: victor@psicoespaco.com.br

2 Doutorando em Educação Física na Universidade Federal do Espírito Santo (UFES). Professor Efetivo da Rede Municipal de Ensino de Vitória. Vitória/Espírito Santo, Brasil. E-mail:rodrigoefrural@hotmail.com

3 Doutoranda em Educação Física pela Universidade Federal do Espírito Santo (UFES). Professora de Educação Física no Colégio Pedro II. Rio de Janeiro/Rio de Janeiro, Brasil. E-mail: kekelfla@yahoo.com.br

4 Doutor em Educação Física. Professor do Centro de Educação Física e Desportos da Universidade Federal do Espírito Santo (UFES). Vitória/Espírito Santo, Brasil. E-mail: andremellovix@gmail.com

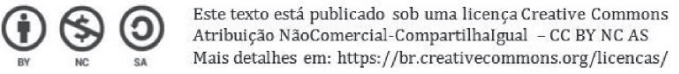


Semiotic analysis of "this is how to be a child" video animation: make-believe game's role on the protagonism and authorship of children

\begin{abstract}
This article focuses on the video animation "This is how to be a child", of Bita's World, available on the social network Youtube ${ }^{\mathrm{TM}}$. The main objective of the study is the analysis, based on this animation, of the role of make-believe type of games on children creations. Creativity, playful activities use and cultural production are some of the traces presented by child chacaracters in the referred video and leads teachers to rethink their pedagogical practices in order to value children 's protagonism in their classes. The analysis's process uses the semiotic method proposed by Charles Sanders Peirce and, according to Children 's Sociology and Everyday's Syudies theories, to interpret the signs and reveal the occult meanings proposed by the authors of this audiovisual material.
\end{abstract}

Keywords: Semiotics. Make-believe. Children's sociology. Everyday life studies

Análisis semiótica del vídeo "asi es ser niño": el papel del juego "haz de cuenta" en el protagonismo y autoria de los niños

\title{
RESUMEN
}

El artículo se centra en el vídeo de animación "Así es ser niño", del Mundo Bita, cuyas exhibiciones suceden en la red social Youtube. El objetivo del estudio es analizar, a partir de esa animación, el papel del juego "haz de cuenta" en las creaciones infantiles. La creatividad, la ludicidad y la producción cultural son algunos rasgos exhibidos por los personajes infantiles en el vídeo en cuestión en este artículo y sirven como reflexión para que los profesores repensen sus prácticas pedagógicas con el fin de valorar el protagonismo de los niños en sus clases. En el proceso de análisis, se utiliza el método semiótico propuesto por Charles Sanders Peirce, en diálogo con la Sociología de la Infancia y con los Estudios del Cotidiano, para la interpretación de los signos y la desocultación de los sentidos propuestos por los creadores de ese material audiovisual.

Palabras-clave: Semiótica. Haz de cuenta. Sociología de la infância. Estudios con el cotidiano

\section{Introdução}

Criada pelo pernambucano Chaps Melo, em 2010, a série animada intitulada "Mundo Bita" destaca, segundo descrição da página oficial no Facebook, ${ }^{5}$ o lado imaginativo

5 O endereço do Mundo Bita no Facebook: https://www.facebook.com/mundobita/ 
das crianças. Grande parte dos vídeos aborda temas de cunho educativo, como o respeito

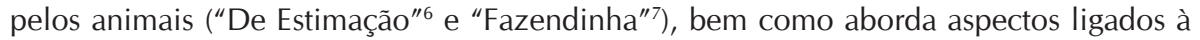
identidade de gênero ("Ele e Ela"8 e "A diferença é o que nos une" ${ }^{\prime \prime}$ ).

As canções foram compostas exclusivamente para os vídeos e são cantadas pelo próprio Chaps Melo. Até o momento da escrita deste artigo, são 53 vídeos/músicas disponíveis no canal oficial do Youtube, ${ }^{10}$ que conta com quase 250 mil inscritos para receber os novos materiais tão logo sejam lançados.

Os vídeos trazem, basicamente, quatro personagens principais. O protagonista, e que dá nome à série, chama-se Bita, um senhor com aspecto bonachão e com um bigode ruivo. Os demais são três crianças, Lila, Dan e Tito. Imagem 1 apresenta os personagens principais da animação:

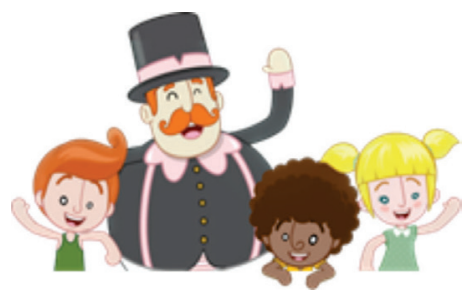

Figura 1 - Personagens do "mundo Bita" Fonte: http://www.mundobita.com.br/

O objetivo do estudo é analisar, a partir dessa animação, o papel do jogo de faz-deconta nas criações infantis. A forma lúdica das crianças enxergarem o mundo, conforme proposto no vídeo, pode colaborar para que professores compreendam o modo como elas produzem cultura, contribuindo para que repensem suas práticas pedagógicas com o intuito de valorizar o protagonismo infantil em suas aulas. Repensar a prática pedagógica implica sensibilizar e ampliar o olhar dos professores para as formas singulares como as crianças representam o mundo, auscultando-as como informantes autorizadas, capazes de agir e pensar sobre si mesmas. Nesse sentido, o vídeo pode se constituir como recurso pedagógico privilegiado para desenvolver "novos olhares" sobre as crianças, contribuindo para superar visões adultocêntricas presentes na Educação Infantil.

Para isso, focalizamos o vídeo "Assim é ser criança", sob o prisma da Sociologia da Infância, sobretudo, a partir dos postulados propostos por Sarmento (2005) e Corsaro

6 O endereço para assistir o vídeo "De Estimação": https://www.youtube.com/watch?v=5TVsXxsFJps\&list=PLe bzEFWI_r62hjOQ13sALsSFMtjz7yb0m\&index = 3

7 O endereço para assistir o vídeo "Fazendinha" https://www.youtube.com/watch? v = cjONzZPJONc\&list = PLe bzEFWI_r62hjOQ13sALsSFMtjz7yb0m\&index =9

8 O vídeo pode ser assistido no link https://www.youtube.com/watch?v=_kjh0Pwc2Ms

9 O vídeo pode ser assistido no link https://www.youtube.com/watch?v= eLtzvypcurE

10 O endereço do canal oficial no Youtube: https://www.youtube.com/channel/UCsr34saf-NXrh11hk4ESRdQ 
(2009), que buscam compreender as crianças como seres plenos de direitos, protagonistas em suas vivências e que não ocupam posições subalternas em relação aos adultos. Recorremos também a Certeau (2014) que, ancorado nos Estudos com o Cotidiano, discute como a criatividade é mobilizada como tática para confrontar o estabelecido, agindo como um ato de resistência, ao ressignificar padrões culturais instituídos.

O método empregado nessa investigação é a semiótica peirceana, cujo objetivo é revelar a produção de sentidos embutidos nos signos, em especial, os que se manifestam no formato de ícones, símbolos e índices. Para isso, nos apoiamos nos escritos do cientista e filósofo norte-americano Charles Sanders Peirce (2015).

Para seleção das cenas analisadas neste estudo, nos baseamos em Rose (2012), para quem os meios audiovisuais, como o vídeo "Assim é ser criança", se constituem de uma sequência complexa de sentidos, na qual se intercalam imagens, sons, cores, edição, legendas e vozes. Para a autora, durante o processo de escolher cenas que representem os ideais de um vídeo, os responsáveis pela seleção devem se preocupar em "[...] descrever os efeitos especiais, tais como música ou mudança na iluminação" (ROSE, 2012, p. 344). Tal preocupação se justifica, uma vez que os efeitos empregados, constituídos pelas dimensões visuais e textuais, são produtores de sentidos e de conteúdos, que precisam ser contemplados na análise a que se propõe realizar.

\section{Sociologia da Infância e estudos com o cotidiano: plenitude, criatividade e produção cultural das crianças}

Compreender as crianças como sujeitos de direitos, eliminando, com isso, a tese de que, uma vez que ainda não chegaram à fase adulta, possuem menor importância social como fontes consultivas e informativas sobre as realidades vividas por elas. Essa é uma das premissas centrais da Sociologia da Infância, que tem como proposta elevar as crianças como seres sociais plenos, cujas vozes devem ser auscultadas, a fim de se investigar suas realidades sociais (SOARES; SARMENTO; TOMÁS, 2005).

Enquadrar as crianças como incapazes de produzir conhecimento e a suposta alegação de que não possuem repertório linguístico devidamente articulado que as habilitem para se comunicar apropriadamente, são argumentos rechaçados por Sarmento (2000, p. 157) ao descrever uma visão social que costuma rotular os mais novos: "[...] a criança é considerada como o não adulto, e esse olhar adultocêntrico sobre a infância registra especialmente a ausência, a incompletude ou a negação das características de um ser humano completo".

Em sentido contrário a essa perspectiva, que encaixilha as crianças como "pequenos adultos", que ocupam um estágio transitório, caracterizado pela dependência e insuficiência, emerge, a partir de 1990, a Sociologia da Infância. De acordo com Assis (2015, p. 26), "[...] a nova Sociologia da Infância propõe a reconstrução do campo e enuncia uma reorientação epistemológica distinta ao conhecimento pericial hegemônico que persistiu durante décadas". A Sociologia da Infância traz consigo uma nova abordagem em relação às 
crianças, promovendo-as como entes sociais produtores de cultura, a partir da observação de seus pontos-de-vista, bem como suas condições sócio-históricas.

Sarmento (2005) contrapõe a tese de que a criança é um "ser-em-devir", ou seja, um ser que ainda não é. De maneira oposta, o autor, assinala as mesmas como um "ser-que-é", tendo como princípio suas plenas competências, potencialidades e modos subjetivos de enxergar o mundo. Sarmento (2005) salienta que, não obstante de receberem uma cultura construída e transmitida pelos adultos, as crianças agem de forma a transformar a produção cultural dada a elas, por intermédio de suas práticas sociais. Nesse mesmo sentido, Corsaro (2009) sinaliza as crianças como protagonistas em suas jornadas, sendo capazes de ressignificar e modificar aspectos culturais mediados pelos adultos, uma vez que as mesmas devem ser percebidas como agentes em sua plenitude e autoras de suas próprias vidas.

Ao se posicionar como um campo que investiga a infância como um objeto sociológico, a Sociologia da Infância aflora descartando, de imediato, as perspectivas de ordem biológica, que acaba por estabelecer uma concepção uniforme, homogeneizante e estereotipada das crianças. Pelo contrário, Sarmento e Pinto (1997) observam que as culturas infantis se forjam em condições diversas, sobretudo, ao que se refere ao sistema de valores, estilos de vida, crenças e representações sociais. A Sociologia da Infância investe nessa multiplicidade de vivências, ao apostar na potência das crianças, cuja produção simbólica, como as linguagens utilizadas no ato de brincar devem ser estimadas, a fim de fornecer traços significadores de suas realidades sociais. No que se refere às brincadeiras, expressão infantil e a relevância de se perscrutar o seus significados, nos fundamentamos em Finco e Oliveira (2011, p. 72), que preconizam:

Apesar de toda bagagem de estereótipos, as crianças pequenas encontram espaços para a transgressão, para a superação e para a expressão de seus desejos. Assim, as crianças pequenas, com seus corpos e com suas espontaneidades, problematizam e questionam esses modelos centrados no adulto.

A partir de Barbosa, Martins e Mello (2017, p. 160), compreendemos que, em face de um repertório que costuma ser julgado como limitado em comparação ao de um adulto, a criança encontra brechas para se expressar e evidenciar sua existência, em especial, quando se manifesta por meio das brincadeiras.

Brincar é uma das principais expressões do comportamento infantil. Por meio dos jogos e das brincadeiras, a criança interage com o seu meio físico e social, constrói conhecimentos, internaliza e produz cultura e também cria e afirma o seu modo peculiar de ser e estar no mundo.

Entre as modalidades de brincadeira, o faz-de-conta torna-se uma prática recorrente das crianças e desponta como uma ação que revela o potencial imaginativo e fantasioso das mesmas. Além de promover o desenvolvimento cognitivo, por meio do jogo do faz-de-conta, a criança fornece elementos que compõem representações externamente instituídas e como são ressignificadas (PINTO, 2011). 
A Sociologia da Infância surge, então, como um campo que visa o reconhecimento das crianças em sua inteireza: como seres que consomem e transformam as produções culturais, cuja interpretação e leitura das relações sociais deva ser consultada, com o intuito de se refletir a respeito de políticas públicas, tal como a formação de currículo escolares. Para Sarmento (2013, p. 14) o raiar da Sociologia da Infância pode ser traduzida como:

[...] uma área científica não apenas legítima, mas influente na produção do conhecimento sobre as crianças e, por consequência, fundante de uma renovada reflexividade institucional sobre a infância, com incidência nas políticas públicas, e, entre elas, nas políticas educativas, na formação de professores e na fundamentação da intencionalidade educativa nas escolas e creches.

Benjamin (1984), em relação à potência inventiva das crianças, registra que elas assimilam os espaços de convívio, relações sociais, bem como as representações da vida ordinária. Contudo, a partir de processos miméticos, as crianças não apenas reproduzem aquilo que é absorvido. Elas transformam suas realidades, deixam suas marcas pessoais e, constantemente, produzem algo novo, que transcende a mera imitação, concedendo a ela a assinatura autoral. "Aceitar o agir social anterior, modifica-lo ou rejeitá-lo integralmente são atitudes que passam pela referência mimética" (WULF, 2016, p. 553). Brincar, nesse sentido, associa-se a uma linguagem construída por elas, dar sentido às coisas que as envolvem, além de representar uma expressão das identidades das próprias.

Sobre a potência inovadora encontrada na linguagem das crianças, nos guiamos em Certeau (2014, p.39), para quem o cotidiano se reinventa de maneira silenciosa e sub-reptícia:
A presença e a circulação de uma representação [...] não indicam de modo algum o que ela é para seus usuários. É ainda necessário analisar a sua manipulação pelos praticantes que não a fabricam. Só então é que se pode apreciar a diferença ou a semelhança entre a produção da imagem e a produção secundária que se esconde nos processos de sua utilização.

Retomamos Certeau (2014), para quem as pessoas recriam o cotidiano de maneira diferenciada. Essas práticas de uso, oriundas daqueles considerados menos aptos, não seguem um roteiro definido de maneira antecipada e adequado à coletividade. Pelo contrário, sua criação, diante das estratégias empregadas, tem como intuito "determinar" a maneira como algo deve ser consumido. Logo, de acordo com Certeau (2014), o consumo traz traços da identidade, uma vez que ao consumir o ator está, necessariamente, produzindo algo.

Esse ato de se rebelar, por meio do consumo, e não se aprisionar pode ser interpretado, a partir de Certeau (2014), como consumo produtivo. Antidisciplinar no sentido de conceder aos seus praticantes o uso de táticas para burlar roteiros previamente estabelecidos: "As táticas do consumo, engenhosidades do fraco para tirar partido do forte, vão desembocar em uma politização das práticas cotidiana" (CERTEAU, 2014, p. 44). Por mais invisíveis que essas manifestações possam aparentar, Certeau (2014) nos informa 
que essas recriações apontam para condição de resistência; expressão política daqueles que a praticam e que não se admitem como seres alienados, dominados e historicamente tachados como domesticados.

\section{Semiótica como metodologia de análise de signos}

Neste tópico, utilizamos o método semiótico proposto por Charles Sanders Peirce (2015), para nos auxiliar a analisar os signos verbais e não-verbais como produtores de sentido, no vídeo "Assim é Ser Criança".

Tudo aquilo que representa algo para alguém é chamado de signo. "Dirige-se a alguém, isto é, cria na mente dessa pessoa, um signo equivalente, ou talvez um signo mais evoluído" (PEIRCE, 2015, p. 46). Uma bandeira branca, por exemplo, pode ter vários significados a partir do contexto que está inserida; em uma guerra, pode representar um ato de trégua. Já em um estádio de futebol de um time que use camisas brancas, como a equipe paulista do Santos ou o espanhol Real Madrid, pode se associar à torcida, cujos atos nem sempre são pacíficos. Essa distinção de cenários faz com que a bandeira branca adquira sentidos distintos e desconectados em relação aos exemplos mencionados. A teoria semiótica do signo tem sua origem no cientista e filósofo norte-americano Charles Sanders Peirce (1839-1914) e nos permite:

[...] penetrar no movimento interno das mensagens, o que nos dá a possibilidade de compreender os procedimentos e recursos empregados nas palavras, imagens, diagramas, sons e nas relações entre eles, permitindo a análise das mensagens em vários níveis (SANTAELLA, 2004, p. 48)

A contribuição da teoria reside na possibilidade de revelar a carga comunicativa de um signo, a partir dos elementos intrínsecos que estão nele contidos, bem como os efeitos desencadeados nos receptores das mensagens. Signo é uma correlação de interconexão, interlocução e interação lógica entre coisas, sentidos e significados. Em suma, o signo "[...] é algo que, para alguém, se inter-relaciona com algo em algum aspecto ou capacidade" (MERRELL, 2003, p. 167).

Volli (2007, p. 34) afirma que os signos não são objetos tocáveis e tangíveis, pelo contrário, no âmbito humano são "[...] construções psíquicas, culturais, dependentes de complexos fatores ligados à aprendizagem". Todo processo de emissão e recepção de signos envolve uma complexa trama de fatores que implicam na produção de sentidos. Essa operação pode ser explicada tomando por fundamento o próprio Peirce (2015, p. 47): "[...] para que algo possa ser um signo, esse algo deve 'representar', como costumamos dizer, alguma outra coisa, chamada seu objeto, apesar de ser talvez arbitrária a condição segundo a qual um Signo deve ser algo distinto de seu objeto".

Ao ensinar para uma criança um gesto que ela não tenha tido acesso até então, por exemplo, como o "joinha", no qual, contraem-se os dedos da mão com o polegar para 
cima, de certa forma, está se atribuindo um sentido para um sinal arbitrário e inventado por alguém. O gesto em si não tem sentido, até se deparar com fatores que interfiram na sua interpretação. Um aceno de mão passa a representar uma despedida; ao se balançar a cabeça lança-se mão de um signo de busca representar uma atitude negativa.

Independente de sua natureza - se manifestados como sons, palavras, marcas - os signos são fundamentais para se estabelecer uma comunicação entre os interlocutores envolvidos em um processo.

A palavra Signo será usada para denotar um objeto perceptível, ou apenas imaginável, ou mesmo inimaginável num certo sentido - pois a palavra 'estrela', que é um Signo, não imaginável, dado que não é esta palavra em si mesma (destaque do autor) que pode ser transposta para o papel ou pronunciada, mas apenas um de seus aspectos, e uma vez que é a mesma palavra quando escrita e quando pronunciada, sendo no entanto uma palavra quando significa 'astro com luz própria' e outra totalmente distinta quando significa 'artista célebre' e uma terceira quando se refere à sorte (PEIRCE, 2015, p. 46-47).

Assim, os signos buscam representar um objeto a alguém ou a qualquer mente potencial. Betti (2007, p. 211) afirma que a produção de signos não é exclusividade humana, "[...] abole-se, portanto, o antropocentrismo e a ruptura entre natureza e cultura. Trata-se agora do Homem do Mundo, e não do Homem no ou diante do Mundo".

\section{As três manifestações do signo para a semiótica peirceana}

Os signos, em que pese atuarem com o intuito de representar algo para alguém, também podem ser classificados em três formas principais, quando correlacionados ao objetivo que estão a representar, indicar ou indiciar. A primeira modalidade é o Ícone. Considera-se um signo icônico aquele que busca representar algo por meio de sua similaridade e semelhança. Uma foto de uma família, a despeito de ser produzida a partir de um processo fotográfico que envolve o controle artificial de luz e softwares de tratamento de imagem, representa visualmente os parentes ali enquadrados na figura, além de não propiciar qualquer tipo de dificuldade para reconhecer seus integrantes. "Qualquer coisa, seja uma qualidade, um existente individual ou uma lei, é Ícone de qualquer coisa, na medida em que for semelhante a essa coisa e utilizado como um seu signo (sic)" (PEIRCE, 2015, p. 52).

A segunda classificação sígnica é o índice, que, como diz o nome, se caracteriza por indicar algo. "Rastros, pegadas, resíduos, remanências são todos índices de alguma coisa que lá passou deixando suas marcas" (SANTAELLA, 1983, p. 66). Um cheiro de alimento, enquanto se caminha em uma calçada, pode, por exemplo, indicar que alguém ali perto está preparando uma refeição. Para que o índice funcione como um signo é preciso interiorizar e compreender alguns fatos da própria vivência, tal qual um barulho de fogos de artifício às 22 horas de uma quarta-feira pode indicar que está acontecendo um jogo de futebol de um time com bastante torcida. 
Outros exemplos: um familiar que entra em casa suado, pode indicar tanto que está muito quente do lado de fora ou então que o mesmo estava praticando exercícios. Essa é uma especificidade do signo índice: não é direto como os demais signos, uma vez que são apresentados indícios e pistas a partir do seu uso, e não uma interpretação fechada e inquestionável.

O terceiro modo de classificação dos signos é o símbolo. Trata-se, segundo Peirce (2015), de um signo que se caracteriza por uma relação de convencionalidade: “Um Símbolo é um signo que se refere ao Objeto que denota em virtude de uma lei, normalmente uma associação de ideias gerais que opera no sentido de fazer com que o Símbolo seja interpretado como se referindo àquele Objeto" (PEIRCE, 2015, p. 52). Logo, os signos simbólicos são algo que dependem de um aprendizado prévio para serem compreendidos. Por exemplo, as placas de trânsito nem sempre possuem uma relação de semelhança com aquilo que representa, como a placa "dê a preferência", que é formada por meio de um triângulo de bordas vermelhas, com o vértice para baixo, e interior na cor branca.

O uso das palavras de um idioma também ilustra o uso do signo simbólico, pois existem regras a serem obedecidas a fim de se construir uma frase dentro das normas cultas.

O caso mais importante e mais estudado de sistema baseado em relações sígnicas arbitrárias é das diferentes linguagens usadas pelas várias sociedades humanas. Exatamente o fato de as numerosas linguagens da humanidade serem tão diversificadas entre si prova a arbitrariedade sobre a qual são construídas. Não existe razão particular alguma para chamar uma mulher de donna em italiano, mulher em português, woman em inglês, ishà em hebraico, mulier em latim, femme em francês e assim por diante. A relação entre significante e significado se explica aqui somente por razões históricas (VOLLI, 2007, p. 44).

Além das placas de trânsito e das palavras, fazem parte do rol dos símbolos e códigos, os gestos, as cores do semáforo, os trajes de roupa específicos para cada evento, os protocolos exigidos em cerimônias, escudos de times, símbolos religiosos, entre outros. Para Peirce (2015), são signos que são estabelecidos de forma arbitrária, muitas vezes, sem um fundamento mais sólido que explique sua criação.

Assim, utilizamos as classificações ícone, índice e símbolo, descritas pela semiótica peirciana para analisar como o vídeo "Assim é ser criança", do Mundo Bita, dialoga com aspectos voltados para a Sociologia da Infância, bem como a criatividade e inventividade, proposta por Michel de Certeau (2014).

\section{Análise semiótica da animação "assim é ser criança"}

Até o momento da redação deste artigo, o vídeo "Assim é ser criança", do Mundo Bita, contabiliza mais de 3.390.000 visualizações ${ }^{11}$ na plataforma Youtube. A Imagem 2 demonstra a página de entrada para o vídeo:

11 Acesso dia 03/11/2017, no link https://www.youtube.com/watch?v=uUgv2bCnbv4 


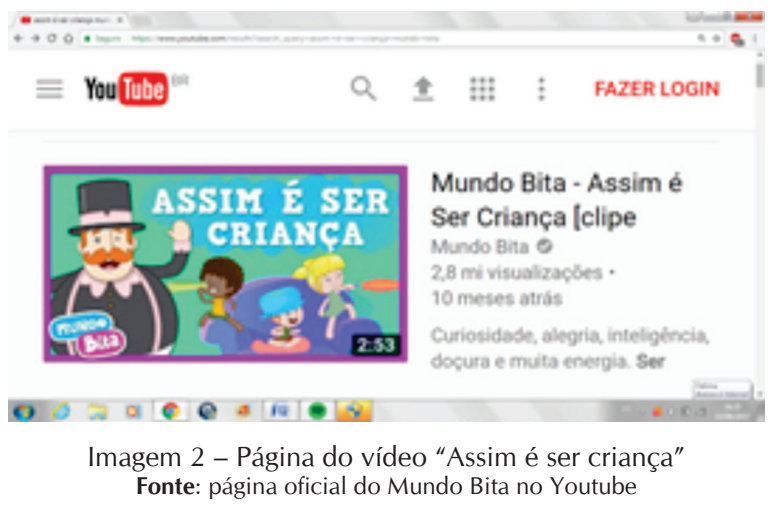

Segundo o texto oficial do canal do próprio Mundo Bita, a música em questão aborda questões ligadas ao universo infantil ${ }^{12}$. A letra da música "Assim é ser criança" é a seguinte:

Tudo é brincadeira, travessura // Nas lentes coloridas da infância // Da nossa maneira, se aventurar // O tempo passa, a gente não se cansa // A vida é um parquinho de diversões // Nossa alegria é alegrar corações // Quem vem conosco nessa nova dança // Viver feliz assim é ser criança // Elas são abelhudas // Tudo que se vê elas querem tocar // Tipo assim curiosas // Todos os porquês elas vão perguntar // A vida é um parquinho de diversões // Nossa alegria é alegrar corações // Quem vem conosco nessa nova dança // Viver feliz assim é ser criança.

O primeiro trecho que analisamos refere-se à Imagem 3, que aparece no início do vídeo, já aos sete segundos de exibição. Nele, a criança chamada Dan aparece com uma panela na cabeça, tendo ao fundo um cenário que, por meio de seus elementos, faz uma referência icônica a copos, jarra de suco, caneca e garrafa térmica. As cores laranja e amarela do fundo nos sugerem, por meio do signo índice, que se trata de uma manhã, em um ambiente que nos remete a uma cozinha, iluminada pelo sol.

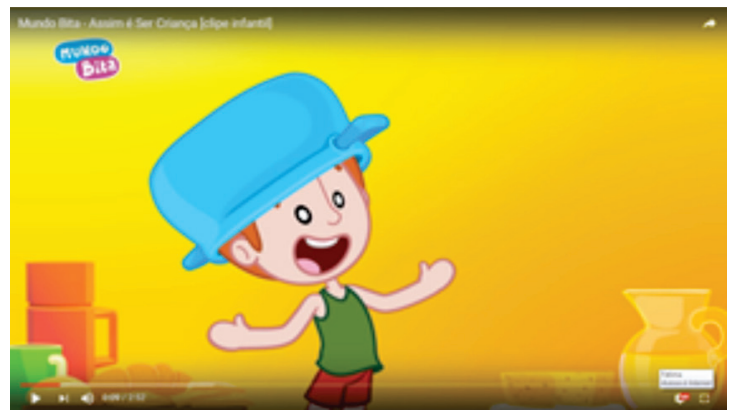

Imagem 3

Fonte: página oficial do Mundo Bita no Youtube 
Do ponto de vista criativo, a utilização dessa cena nos sugere, por meio do signo índice, que ela teve inspiração/referência na obra "O menino maluquinho", do cartunista Ziraldo. Nas Imagens 4 e 5, da esquerda para a direita, visualizamos, respectivamente, a capa do livro e a capa do DVD do filme "O menino maluquinho". O fundo amarelo e a panela na cabeça do vídeo "Assim é ser criança" sustentam a nossa tese de que são elementos que buscam aproximação com a obra de Ziraldo.

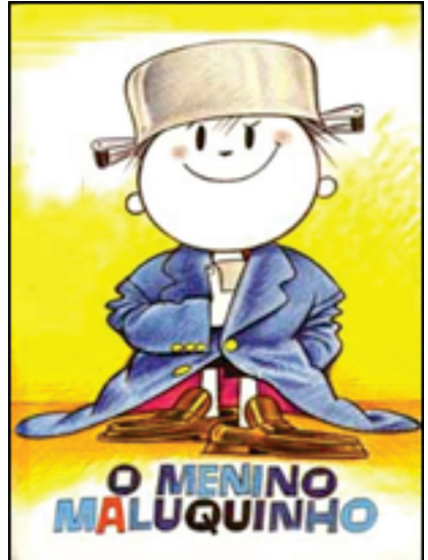

Imagem 4 - Capa do Livro Fonte: www.ziraldo.com

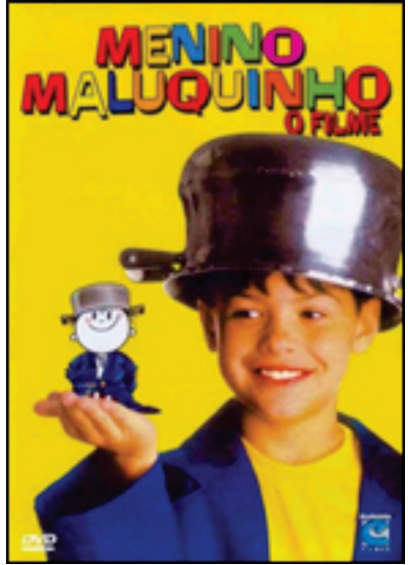

Imagem 5 - Capa do DVD Fonte: www.adorocinema.com

O livro Menino Maluquinho narra a história de uma criança muito imaginativa, ativa e brincalhona, que se notabiliza pelo exercício do faz-de-conta (PINTO, 2011). São esses tópicos que o criador do "Assim é ser criança" almeja que migrem para o seu vídeo e sejam reconhecidos pela audiência que o assiste.

Nessa acepção, nos embasamos em Barbosa, Martins e Mello (2017) que afirmam que a brincadeira é uma expressão viva e legítima das crianças. Conforme nos orienta a Sociologia da Infância, a criança deve ser contemplada com seres plenos em suas jornadas, de maneira que a visão de que são humanos em estágios transitórios (ou pequenos adultos) deve ser eliminada.

O uso de uma panela na cabeça, como se fosse um chapéu, embora ressalvemos que, nessa análise tende a se aproximar mais da obra de Ziraldo do que a do Mundo Bita, se alinha ao postulado de Sarmento (2005) e Corsaro (2009) que sublinham a capacidade de ressignificar e transformar os aspectos culturais, que são dados às crianças, e que esse olhar tem relevante valor simbólico, ao atribuir novas funcionalidades àquilo que é tido como convencional. Segundo Certeau (1985), essas práticas cotidianas, como mostrado na ação da criança, evidenciam a face criativa e transformadora do homem ordinário, podendo assumir três aspectos: o estético, ético e polêmico. 
Pelo estético, tal qual a panela assumindo a função de chapéu, compreende-se a perspectiva estilística, que confere a um ato uma expressividade ímpar, a partir de um manejo singular dos elementos que nos são colocados à disposição. "Trata-se também de uma arte, justamente uma arte que tem como característica ser fundamentalmente uma arte do fazer. Isto é, que não se traduz num discurso, mas sim em um ato" (CERTEAU, 1985, p. 7).

A Imagem 5, recortada do décimo ao décimo quarto segundo, ocorre em um ambiente repleto de livros, na qual a criança, cujo nome é Tito, pega algumas folhas de papel e as enrola fazendo delas uma espécie de luneta ou telescópio. Do ponto de vista semiótico a cena sugere, na perspectiva do signo indicial, ser passada em uma biblioteca, que, por sua vez, costuma ser associada a um ambiente mais sóbrio e frequentada por adultos.

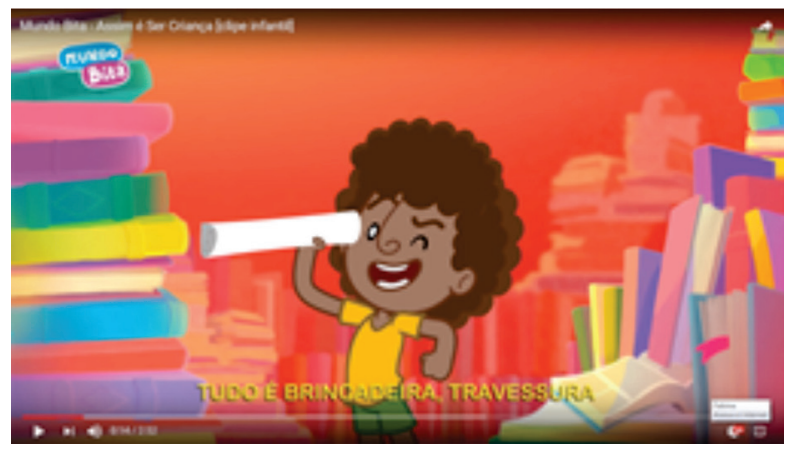

Imagem 5 - Criança na biblioteca

Fonte: página oficial do Mundo Bita no Youtube

Novamente, recorremos ao signo indicial para sinalizar que a presença do Tito, junto aos livros, trata-se de uma tentativa de se inserir uma criança em um ambiente que, em tese, não é próprio dela. No entanto, ao dar uma nova função ao papel, transformando-o em uma luneta, a criança assume o seu lado "explorador". O episódio faz referência às aventuras dos descobridores marítimos que, do ponto de vista do signo simbólico, ficam marcados nas narrativas históricas como "descobridores". Salientamos, por considerarmos relevante, que esse trecho vem escoltado pela letra da música "Tudo é brincadeira, travessura, nas lentes coloridas da infância", o que, por sua vez, acentua o caráter inventivo das crianças.

Esse ato de converter o papel, cuja função primordial é a leitura ou a escrita, em uma luneta nos remete à proposição de consumo produtivo, descrito por Certeau (2014). Ao subverter a funcionalidade estabelecida de um papel, Tito produz algo novo, não prescrito em manuais, o que, de certa forma, colabora para circunscrever traços da sua identidade como criador. Logo, baseando-nos em Certeau (1985), adquire nuances de um consumo de caráter ético. Em relação ao caráter ético assinalamos como "[...] uma maneira de o agente se recusar a ser identificado à ordem tal como ela se impõe" (CERTEAU, 1985, p. 7). Logo, é a manifestação que se rebele em relação ao estabelecido; de mudar um panorama estabelecido de antemão. "Isto é, uma vontade histórica de existir" (CERTEAU, 1985, p. 07). 
Para buscar mais explicações sobre a intencionalidade dessa cena, que faz do papel uma luneta, nos apoiamos também em Finco e Oliveira (2011), ao afirmarem que a brincadeira infantil, além de representar um modo de expressar desejos, é uma maneira encontrada pelas mesmas para questionar, problematizar e desafiar toda a bagagem de estereótipos imputada pelos adultos.

A fim de ilustrar essa proposição, trazemos para investigação as Imagens 6 e 7 que permitiram análises semelhantes. Na Imagem 6, que ocorre entre os $14^{\circ}$ e $20^{\circ}$ segundos, as três crianças, Dan, Tito e Lila (da esquerda para direita) estão sobre um animal difícil de ser classificado, que se assemelha a algo metade cavalo, metade ave. Lila e Tito parecem estar na mesma brincadeira, enquanto o Dan está com a sua "luneta" interpretando o papel de explorador, como já mostrado, fazendo associação com o lado descobridor. A cena é concluída com a inserção do Bita (Imagem 7), o senhor de bigode, que traz uma bandeja com doces e que tem ao fundo as três crianças brincando no sofá.

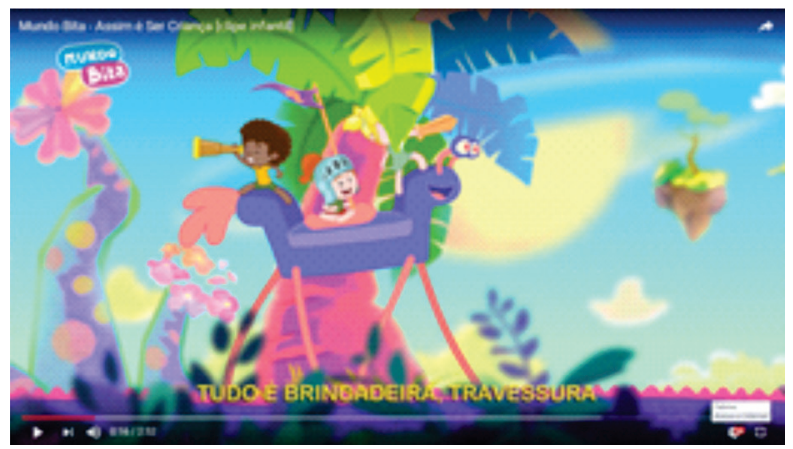

Imagem 6

Fonte: página oficial do Mundo Bita no Youtube

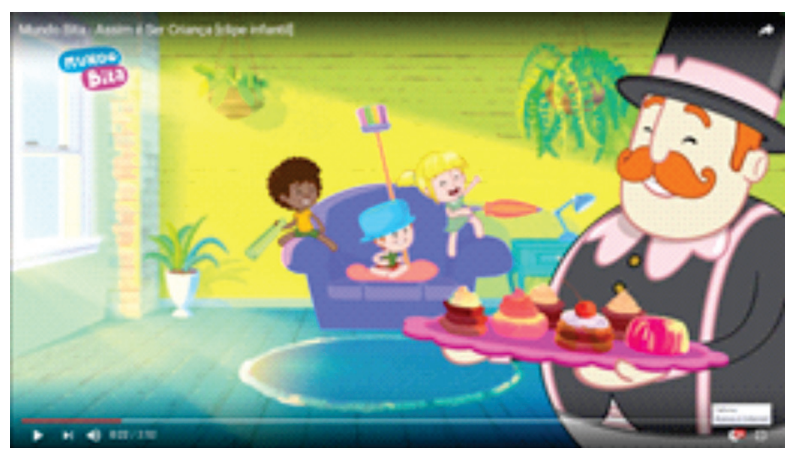

Imagem 7

Fonte: página oficial do Mundo Bita no Youtube 
Em outra imagem selecionada (Imagem 8), aos 28 segundos do vídeo, Dan está com uma roupa de astronauta e se depara com um suposto alienígena, que logo o lambe. No entanto, aos 32 segundos a cena muda para o Bita observando na janela um cachorro lambendo o Dan (Imagem 9).

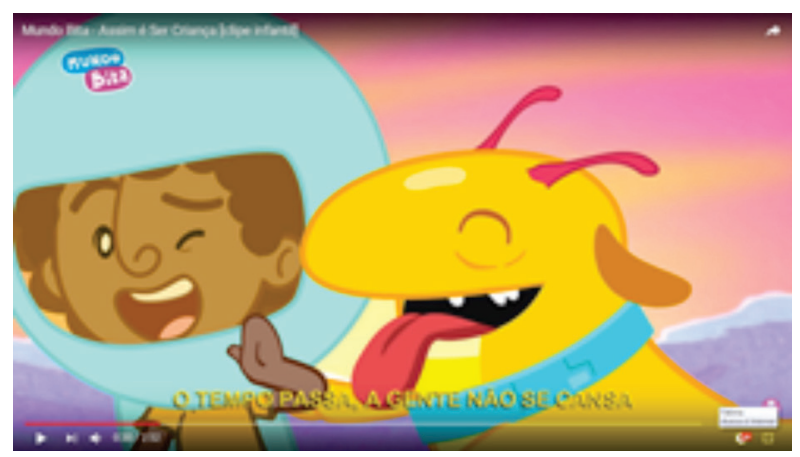

Imagem 8

Fonte: página oficial do Mundo Bita no Youtube

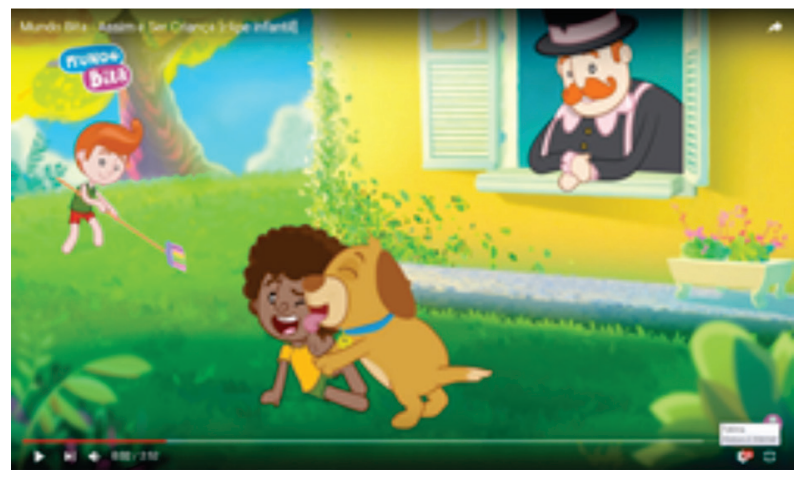

Imagem 9

Fonte: página oficial do Mundo Bita no Youtube

Em ambas as imagens (8 e 9), faz-se um contraponto a partir da inserção do Bita, o senhor que dá nome à série. Do ponto de vista semiótico, sugere-se, por meio do signo índice, que a entrada do humano mais velho (Bita) faz com o potencial imaginativo das crianças seja dissolvido e o olhar torna a ser o adultocêntrico, o que, por sinal, a Sociologia da Infância se propõe a contrapor. Curiosamente, em outros momentos do vídeo, todavia não elencados para esse artigo, essa ponte entre o faz-de-conta (visão das crianças) e o real (olhar de adulto) ocorre, o que nos remete ao aspecto polêmico das práticas cotidianas, a partir do ponto de vista infantil. Para Certeau (1985), a dimensão polêmica trata-se, 
basicamente, de uma ação de sobrevivência; "[...] uma defesa para a vida" (p. 7). Envolve a estratégia utilizada pelos mais fracos para enfrentar os mais poderosos. Se as condições materiais se apresentam de forma assimétrica entre os membros de uma sociedade, é por meio da face polêmica que as pessoas que não fazem parte dos mais favorecidos demonstram sua arte, através das forças existentes, como se fixar como consumidores.

Adiante, aos 2 minutos e 22 segundos, há uma cena em que as crianças passeiam no já mencionado animal (meio cavalo, meio ave). Porém, dessa vez, o senhor Bita também aparece em cena, como se ele também estivesse fazendo parte do universo infantil. Do ponto de vista semiótico, essa cena sugere, como signo indicativo, que Bita aceita fazer parte do universo das crianças, deixando de lado um pensamento que promova uma dualidade entre as realidades dos adultos e das crianças.

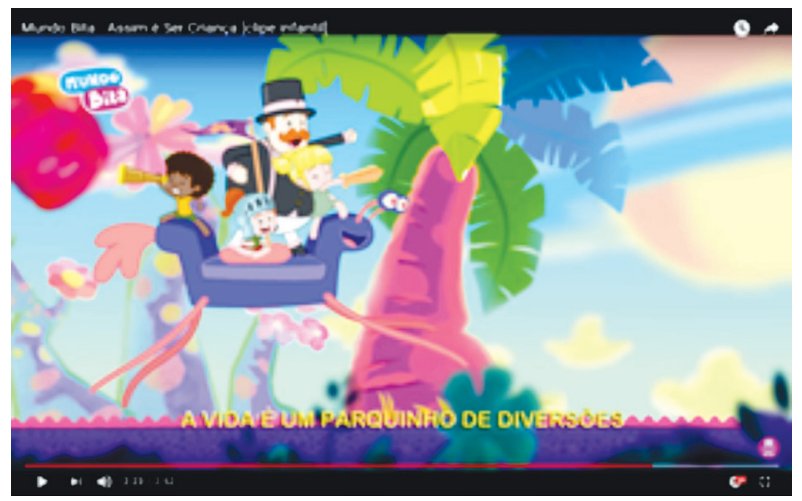

Imagem 10 - Bita inserido no universo infantil

Fonte: página oficial do Mundo Bita no Youtube

Assinalamos esse trecho, no qual Bita se insere no universo infantil, como bastante significativo na análise do vídeo. Por se localizar nos segundos finais da exibição, pode nos tencionar para o grande desafio proposto pela Sociologia da Infância, como área científica, que reconhece a criança como "ser-que-é" em sua completude e protagonismo, bem como considera sua interpretação do mundo e relações sociais por elas engendradas (SARMENTO, 2013).

Não obstante considerarmos que, segundo o método semiótico, há inúmeras possibilidades de interpretação por parte da audiência ao assistir a animação em questão, acreditamos que, nesse instante, Bita passa a fazer parte, em condições simétricas às das crianças, de um cenário assentado no pensamento lúdico de Dan, Tito e Lila. Acompanhada da letra da música "A vida é um parquinho de diversões", as crianças em questão reinventam seu cotidiano, transformaram suas realidades e se colocam como produtoras culturais (CERTEAU, 2014), ao fazerem da sala de estar da casa, geralmente um lugar de encontros protocolares, um lugar para ampliação do espectro criativo. A atmosfera de faz-de-conta abre espaço para o imaginativo e fantasioso onde o espaço da ação é ressignificado a partir do olhar das crianças e do Bita, que adota a ótica infantil na cena (PINTO, 2011). 


\section{CONSIDERAÇÕES FINAIS}

Ao se inserir como um campo científico que reconhece as crianças como seres plenos, relevantes e significativos em suas trajetórias de vida, a Sociologia da Infância denuncia questões relacionadas à não inserção das mesmas como fontes válidas de pesquisas. Sobre elas, recai a crença de serem humanos ainda em fase de transição, que não alcançaram a "maturidade" do estágio adulto. Mais que ignoradas, as crianças tendem a ser descartadas como objeto de investigação sociológica.

A breve análise do vídeo "Assim é ser criança", do Mundo Bita, em muitos pontos, dialoga com as premissas propostas por autores como Sarmento (2005) e Corsaro (2009), cujos escritos fornecem base para os termos apontados pela Sociologia da Infância. No vídeo em questão, é apontada a visão binária entre a perspectiva infantil e a adulta. De um lado, tópicos que valorizam o imaginativo, a ressignificação criativa e o lúdico, do outro, a racionalidade à mostra.

A inventividade e a pulsação brincante das crianças fazem coro ao consumo criativo assinalado por Certeau (2014), para quem, o cotidiano é reinventado a partir de seres dotados de talentos para transformar as realidades culturais oportunizadas a eles. Enxergar um telescópio em uma folha de papel ou converter um espaço interno, como uma sala de estar, em uma área aberta para se passear com um quadrúpede, metade cavalo metade ave, é não se contentar com aquilo que é apresentado (ou imposto) como inquestionável. A brincadeira de faz-de-conta, mostrado no vídeo em análise, permite que a criança fantasie, crie e recrie o mundo do seu jeito. A riqueza das representações imaginativas dos pequenos, por seu turno, lança o desafio para que os professores assumam a perspectiva do outro, nesse caso, as crianças (PINTO, 2011).

Rever paradigmas relacionados a uma suposta incapacidade e inferioridade das crianças é condição sine qua non para quem labuta os ideais da Sociologia da Infância. O desafio de enxergar os mundos infantis a partir das perspectivas dos pequenos, contemplando, assim, seus desejos e inquietações é algo que pode contribuir para diminuir a visão predominantemente adultocêntrica, que não costuma contemplar a opinião dos mais novos, inclusive em questões relacionadas à sua formação educacional.

Com base nas discussões aqui empreendidas, é possível extrair reflexões acerca do trabalho pedagógico com as crianças, em especial, na Educação Infantil. As Diretrizes Curriculares Nacionais para a Educação Infantil (BRASIL, 2009) e a Base Nacional Curricular Comum (BRASIL, 2017) orientam que a dinâmica curricular nas instituições infantis deve estar centrada nas crianças, sobretudo, nos seus modos peculiares de representar e operar no mundo. Nesse sentido, o vídeo do Mundo Bita ajuda a compreender como as crianças podem se tornar autoras de suas próprias vidas, produtoras de cultura e protagonistas em seus processos de socialização, lançando aos professores o desafio de potencializar as brincadeiras de faz-de-conta em suas mediações pedagógicas com a Educação Infantil. Reconhecer a necessidade de existir dos infantis, bem como permitir que se estabeleçam como autores de suas histórias: "assim é ser criança". 


\section{REFERÊNCIAS}

ASSIS, Lívia Carvalho. Por uma perspectiva pedagógica para intervenção da Educação

Física com a Educação Infantil. 181 fls. Dissertação (mestrado em Educação Física). Universidade Federal do Espírito Santo. Vitória, 2015.

BARBOSA, Raquel Firmino Magalhães; MARTINS, Rodrigo Lema Del Rio; MELLO, André da Silva. Brincadeiras lúdico-agressivas: tensões e dificuldades no cotidiano da Educação Infantil. Movimento, Porto Alegre, v. 23, n. 1, p. 159-170, jan./mar. de 2017.

BENJAMIN, Walter. Reflexões: a criança, o brinquedo, a reflexão. São Paulo: Summus, 1984 BETTI, Mauro. Educação Física e cultura corporal do movimento. Revista da Educação Física/UEM, Maringá, v. 18, n. 2, p. 207-217, 2. sem. 2007.

BRASIL. Conselho Nacional de Educação. Resolução CNE/CEB $n^{0}$ 5/2009. Diretrizes Curriculares Nacionais para a Educação Infantil. Brasília: Diário Oficial da União, 2009. BRASIL. Ministério da Educação. Secretaria da Educação Básica. Base nacional comum curricular. Terceira versão. Brasília, 2017. Disponível em: < http://basenacionalcomum. mec.gov.br/\#/site/inicio >. Acesso em: 23 mar. 2018.

CERTEAU, Michel de. A invenção do cotidiano: artes do fazer. 22 ed. Petrópolis, RJ: Vozes, 2014.

. Teoria e método no estudo das práticas cotidianas. In: ENCONTRO COTIDIANO, CUltura POPUlar E Planejamento URBANO, 1985, São Paulo, Anais... São Paulo: FAU/USP, 1985, p. 3-19.

CORSARO, William. Reprodução interpretativa e cultura de pares. In: MULLER, Fernanda; CARVALHO, Ana Maria. (Org.), Teoria e prática na pesquisa com crianças: diálogos com William Corsaro. São Paulo: Cortez, 2009.

FINCO, Daniela; OLIVEIRA, Fabiana. A sociologia da pequena infância e a diversidade de gênero e de raça nas instituições de educação infantil. In: FARIA, Ana Lúcia Goulart de; FINCO, Daniela. (Org.), Sociologia da infância no Brasil. Campinas: Autores Associados. p. 55-80.

MERRELL, Floyd. Iúri Lótman, C. S. Peirce e semiose cultural. Galáxia, São Paulo, n. 3, p. 163-185, abril, 2003.

PEIRCE, Charles Sanders. Semiótica. São Paulo: Perspectiva, 2015.

PINTO, Ana Virgínia Gomes de Souza. A brincadeira de faz-de-conta e a teoria da mente.

Revista Anagrama: Revista Científica Interdisciplinar de Graduação. Ano 4, mar./ maio, 2011.

ROSE, Diana. Análise de imagens em movimento. In: BAUER, Martin W; GASKELL, George

(Org.). Pesquisa qualitativa com texto, imagem e som: um manual prático. 10. Ed. Petrópolis: Vozes, 2012. p. 343-364.

SANTAELLA, Lúcia. O que é semiótica. São Paulo: Brasiliense, 1983.

. Teoria geral dos signos: como as linguagens significam as coisas. São Paulo:

Pioneira Thomson Learning, 2004. 
SARMENTO, Manuel Jacinto. Os ofícios da criança. In: Congresso Internacional "Os Mundos Sociais e Culturais da Infância", 2, 2000, Braga. Anais... Braga: Instituto de Estudos da Criança da Universidade do Minho. v. II. p. 125-145.

. Gerações e alteridade: interrogações a partir da sociologia da infância. Educação \& Sociedade, Campinas, v. 26, n. 91, p. 361-378, maio/ago. 2005.

. A sociologia da infância e a sociedade contemporânea: desafios conceituais e praxeológicos. ENS, Romilda Teodoro; GARANHANI, Marynelma Camargo (Org.). Sociologia da Infância e a formação de professores. Curitiba: Champagnat, 2013, p. 13-46.

SARMENTO, Manuel Jacinto; PINTO, Manuel. As crianças e a infância: definindo conceitos, delimitando o campo. In: SARMENTO, Manuel Jacinto; PINTO, Manuel. As crianças: contextos e identidades. Braga: Universidade do Minho, 1997. p. 265-293.

SOARES, Natalia Fernandes; SARMENTO, Manuel Jacinto; TOMÁS, Catarina. Investigação da infância e crianças como investigadoras: metodologias participativas dos mundos sociais das crianças. Nuances: estudos sobre educação - ano XI, v. 12, n. 13, jan./ dez. 2005.

VOLLI, Ugo. Manual de semiótica. São Paulo: Edições Loyola, 2007.

WULF, Christoph. Aprendizagem cultural e mimese: jogos, rituais e gestos. Revista Brasileira de Educação, v. 21, n. 66, jul./set. 2016.

Recebido em: Novembro/2017

Aprovado em: Maio/2018 